\title{
Calcitonin levels by ECLIA correlate well with RIA values in higher range but are affected by sex, TgAb, and renal function in lower range
}

\author{
Yuko Ito ${ }^{1), 2)}$, Hiromi Kaneko(1),3), Yoshikazu Sasaki ${ }^{3)}$, Noboru Ohana ${ }^{1), 3)}$, Masashi Ichijo ${ }^{4)}$, \\ Fumihiko Furuya $^{4)}$, Satoru Suzuki ${ }^{2)}$, Shinichi Suzuki²,5) and Hiroki Shimura ${ }^{1), 2)}$ \\ 1) Department of Laboratory Medicine, School of Medicine, Fukushima Medical University, Fukushima 960-1295, Japan
2) Thyroid and Endocrinology Center, Fukushima Medical University Hospital, Fukushima 960-1295, Japan
3) Department of Clinical Laboratory Medicine, Fukushima Medical University Hospital, Fukushima 960-1295, Japan
4) Third Department of Internal Medicine, Faculty of Medicine, University of Yamanashi, Yamanashi 409-3898, Japan
5) Department of Thyroid and Endocrinology, School of Medicine, Fukushima Medical University, Fukushima 960-1295, Japan
}

Abstract. Calcitonin (CT) is a marker for both initial diagnosis and monitoring of patients with residual or recurrent medullary thyroid carcinoma (MTC). In Japan, serum CT had been measured by radioimmunoassay (RIA) until recently. Electrochemiluminescence immunoassay (ECLIA) became commercially available in 2014, and this technique is now the only method used to examine CT concentration. The purposes of this study were to investigate the correlations between the CT concentration measured with ECLIA (ECLIA-CT) and RIA (RIA-CT) and to explore the clinical characteristics of patients with elevated ECLIA-CT. CT concentrations of 348 sera samples from 334 patients with various thyroid disorders including nine MTC were measured using both assays. The correlation analysis revealed an excellent correlation between ECLIA-CT and RIA-CT among the cases with CT level $>150 \mathrm{pg} / \mathrm{mL}$ by both assays $\left(r_{\mathrm{s}}=0.991, p<0.001\right)$. However, $63 \%$ of all samples exhibited undetectable ECLIA-CT, while their RIA-CTs were measured between 15 and $152 \mathrm{pg} / \mathrm{mL}$. The ECLIA-CTs in all patients who underwent total thyroidectomy for non-MTC showed low concentrations. High ECLIA-CT was observed in patients with MTC or pancreas neuroendocrine tumor. ECLIA-CT was also increased in 14 other male patients with nonMTC, including four with renal failure. Multivariate logistic regression analysis showed that male sex, negative $\mathrm{TgAb}$, and lower estimated glomerular filtration rate were independent factors to predict detectable ECLIA-CT $(\geq 0.500 \mathrm{pg} / \mathrm{mL})$. These results indicate that ECLIA-CT correlates well with RIA-CT in higher range and is affected by sex, $\mathrm{TgAb}$, and renal function.

Key words: Calcitonin, Medullary thyroid carcinoma, Electrochemiluminescence immunoassay (ECLIA), Radioimmunoassay (RIA)

CALCITONIN (CT) is a 32-amino acid monomeric peptide secreted from the parafollicular cells (C-cell) of the thyroid gland, and is measured as a clinical marker of medullary thyroid carcinoma (MTC), a malignancy derived from thyroid C-cells. CT is also used for treating hypercalcemia, due to its inhibition of bone resorption and its enhancement of renal calcium excretion [1].

CT was discovered in 1962 as a substance that can decrease serum calcium concentration $[2,3]$. Then, in the 1970 s, radioimmunoassay (RIA) was developed to meas-

Submitted Dec. 26, 2019; Accepted Mar. 5, 2020 as EJ19-0610 Released online in J-STAGE as advance publication Apr. 8, 2020 Correspondence to: Hiroki Shimura, MD, PhD, Department of Laboratory Medicine, School of Medicine, Fukushima Medical University, 1 Hikarigaoka, Fukushima-shi, Fukushima 960-1295, Japan.

E-mail: hshimura@fmu.ac.jp ure $\mathrm{CT}$ in humans $[4,5]$. This technique led to: the observation that the level of CT was increased in the serum of patients with MTC; and the demonstration that these levels were further augmented after iv calcium and/or pentagastrin administration [6]. On the other hand, Body et al. reported nonspecific increases in plasma immunoreactive calcitonin in healthy individuals [5]. In addition to CT, the serum of healthy persons contains procalcitonin (ProCT) and other CT precursors. These precursors may be increased in some clinical conditions, such as MTC, other neuroendocrine tumors, inflammation, systemic infection and sepsis [7].

$\mathrm{CT}$ is regarded as a marker for both preoperative diagnosis and postsurgical management of MTC; therefore, accuracy is required when measuring CT level. Over the past few decades, commercial assays for measuring CT have progressed to immunochemiluminometric assays 
(ICMAs), which are highly sensitive and specific for monomeric CT. Regarding ICMAs, cross-reactivity with ProCT or other calcitonin-related peptides is largely eliminated [8]. In Japan, the RIA method had been the only assay to measure $\mathrm{CT}$ concentrations for clinical test until recently. ECLusys ${ }^{\circledR}$ Calcitonin (Roche Diagnostics K.K., Japan), based on electrochemiluminescence immunoassay (ECLIA), became commercially available in September 2014, and supply of reagents for RIA was terminated in March 2016. Today, it is possible to measure CT concentrations in a general laboratory, without the need for a radiation protection facility, and to examine CT concentration more rapidly than before.

Nevertheless, there have not been enough studies comparing CT concentrations obtained via RIA (RIA-CT) and ECLIA (ECLIA-CT), or those evaluating CT levels measured by ECLIA. Therefore, in the present study, using the two assays, we measured CT levels in serum samples from patients with various thyroid disorders, then investigated the correlations between the two methods. Furthermore, we explored the clinical factors influencing elevation of ECLIA-CT in non-MTC patients.

\section{Materials and Methods}

\section{Subjects}

Surplus sera that underwent thyroid or ProCT tests were obtained from Fukushima Medical University Hospital, Aidu Chuo Hospital and Fukushima Rosai Hospital, between October 2015 and March 2016. Sera from patients with MTC were also obtained from University of Yamanashi Hospital between 2012 and 2016.

A total of 348 serum samples from 334 patients were studied. When multiple samples from one patient were available, the earliest sample was used for the analyses of correlations with clinical data. Patients' clinical information, including age, sex, clinical and pathological diagnosis, history of surgical therapy, laboratory data, and clinical course, was collected from their medical records. The study population included patients with thyroid disease or parathyroid disease, as well as patients with increased ProCT levels.

Regarding classification of thyroid diseases, MTC, follicular thyroid carcinoma (FTC) and follicular adenoma (FA) were determined based on pathological diagnosis of the surgical specimens. Papillary thyroid carcinoma (PTC) was diagnosed not only by resected specimens but also by fine-needle aspiration cytology. Lymphoma was diagnosed by core needle biopsy. The MTC group included all patients who had been diagnosed as having MTC, even after surgery. The FTC and PTC groups consisted of untreated patients and thyroidectomized patients with metastasis. Patients with thyroid nodules that were diagnosed as neither malignant nor suspicious for malignancy by aspiration cytology and were not diagnosed as malignant by ultrasonography were classified into a benign nodule group. The Graves' disease (GD) group consisted of patients with GD, even in remission. The Hashimoto's thyroiditis (HT) group included not only patients with hypothyroidism but also those with normal thyroid function. Patients with nodular diseases coexisting with autoimmune thyroiditis were classified into a nodular disease group. Patients who had undergone total thyroidectomy because of GD, PTC without metastasis, or multiple benign nodules were categorized into the athyroid group. The normal thyroid group was defined as a group of subjects with thyroid glands that had normal thyroid function and no abnormal finding with ultrasonography. If no information on the thyroid was obtained, the patient was categorized into the unknown group.

\section{Laboratory testing}

The serum samples were stored at a temperature of $-80^{\circ} \mathrm{C}$ until testing. They were thawed only once, at the time of measurement.

In each of the 348 serum samples, CT was measured by both RIA (Calcitonin RIA LSIM ${ }^{\circledR}$, LSI Medience Corporation, Japan) and ECLIA (ECLusys ${ }^{\circledR}$ Calcitonin, Roche Diagnostics K.K., Japan). Anti-TSH receptor antibody (TRAb), anti-thyroglobulin antibody (TgAb), antithyroid peroxidase antibody (TPOAb) and thyroglobulin in each sample were measured by ECLIA technique. The ECLIA-CT reference range used was that previously reported by Kitagawa et al. [9], and the RIA-CT reference range was provided by BML, INC. (Tokyo, Japan) (Supplementary Table 1).

For analysis of the clinical factors that affect ECLIA$\mathrm{CT}$, we used only samples that also had available data on parathyroid hormone (intact-PTH), serum calcium, or serum creatinine, and had been assayed at Fukushima Medical University Hospital. Intact-PTH was measured by ECLIA. Serum calcium level was corrected by albumin level. Renal function was evaluated by the Japanese estimated glomerular filtration rate (eGFR). The equation for eGFR used is shown below [10].

eGFR $\left(\mathrm{mL} / \mathrm{min} / 1.73 \mathrm{~m}^{2}\right)=194 \times$ Serum creatinine $^{-1.094}$ $\times \mathrm{Age}^{-0.287} \times 0.739$ (if female)

ProCT was measured by Liquid-phase Binding Assay and Electrokinetic Analyte Transport Assay (LBAEATA) ( $\mu$ TAS Wako BRAHMS PCT $^{\circledR}$, Wako Pure Chemical Industries, Ltd. Japan).

\section{Statistical analysis}

Standard major axis regression was used to determine the regression equation between RIA-CT and ECLIA-CT 
and was calculated using the program 'ValidationSupport/Excel Ver. 3.5', provided by the Japanese Society of Clinical Chemistry. We carried out the other statistical analyses by using the statistical software IBM SPSS Statistics 26 (IBM, Armonk, NY, USA).

Nonparametric tests were used to analyze correlations between ECLIA-CT and each continuous variable, and to compare the ECLIA-CTs in categories of clinical and laboratory findings. Serum samples of patients with MTC or neuroendocrine tumor, and samples of those after total thyroidectomy were excluded. TRAb, TgAb, and TPOAb were categorized into two groups according to titer; positive or negative. Intact-PTH, serum calcium and thyroglobulin were categorized into four groups according to their quartiles. eGFR was classified into four groups based on GFR categories in the chronic kidney disease (CKD) guidelines [11], <30, 30-59, 60-89, and $\geq 90 \mathrm{~mL} / \mathrm{min} / 1.73 \mathrm{~m}^{2}$. To determine the variables associated with ECLIA-CT $\geq 0.500 \mathrm{pg} / \mathrm{mL}$, logistic regression analysis was performed using categorical variables. Because ECLIA-CTs were undetectable in more than half of the total samples, and there were a few cases whose ECLIA-CTs were above the reference range, ECLIA-CTs were divided into two categories; detectable $(\geq 0.500 \mathrm{pg} / \mathrm{mL})$ and undetectable $(<0.500 \mathrm{pg} / \mathrm{mL})$.

In all analyses, a $p$ value of $<0.05$ was considered statistically significant. Values below or above the measurement range were calculated as the limit value; for example, CT $<0.500 \mathrm{pg} / \mathrm{mL}$ was regarded as $0.500 \mathrm{pg} / \mathrm{mL}$.

\section{Results}

\section{Demographic data}

A total of 334 patients ( 89 males and 245 females; median age 56.5 [39.0-68.0] [range 9-91 years]) were included in the present study. Nine had MTC, 47 had PTC, eight had FTC, two had FA, and two had lymphoma. Single or multiple nodules that were regarded as benign nodules were found in 134 patients, including three patients with autonomously functioning thyroid nodules (AFTNs). Eight had only simple cysts. GD and HT were diagnosed in 62 and 36 patients, respectively. Four patients had other thyroid diseases. Seven patients each were categorized into the athyroid group and the normal thyroid group. There was no information on the thyroids of eight patients (Table 1).

There were seven cases with increased ProCT, five of which belonged to the unknown group, with the remaining two belonging to the benign nodule group. ProCT levels ranged from 32.29 to $86.29 \mathrm{ng} / \mathrm{mL}$ (reference range; $\leq 0.05 \mathrm{ng} / \mathrm{mL}$ ). Among the seven patients with increased ProCT, five were clinically diagnosed as hav-
Table 1 Demographic data

\begin{tabular}{lcc}
\hline Clinical diagnosis & $N($ female/male $)$ & Age \\
\hline MTC & $9(6 / 3)$ & $52.0(29-73)$ \\
PTC & $47(34 / 13)$ & $23.0(9-79)$ \\
FTC & $8(4 / 4)$ & $65.0(56-85)$ \\
\hline FA & $2(2 / 0)$ & $19.0(18-20)$ \\
Thyroid lymphoma & $2(1 / 1)$ & $75.5(72-79)$ \\
\hline Benign nodule or AFTN & $134(108 / 26)$ & $59.0(10-91)$ \\
Cyst & $8(4 / 4)$ & $63.5(22-84)$ \\
\hline GD & $62(48 / 14)$ & $51.0(16-88)$ \\
HT & $36(25 / 11)$ & $60.5(12-83)$ \\
\hline Others* & $4(2 / 2)$ & $61.0(40-79)$ \\
\hline Normal thyroid & $7(3 / 4)$ & $48.0(21-72)$ \\
\hline Unknown & $8(2 / 6)$ & $58.5(11-77)$ \\
\hline Athyroid & $7(6 / 1)$ & $57.0(39-75)$ \\
\hline Total & $334(245 / 89)$ & $56.5(9-91)$ \\
\hline Afo &
\end{tabular}

Age is presented as median and range (years).

$N$, number; MTC, medullary thyroid carcinoma; PTC, papillary thyroid carcinoma; FTC, follicular thyroid carcinoma; FA, follicular adenoma; AFTN, autonomously functioning thyroid nodule; GD, Graves' disease; HT, Hashimoto's thyroiditis

*Others include thyroid diseases such as painless thyroiditis, subacute thyroiditis, IgG4-related thyroiditis and hypopharyngeal cancer invasion into the thyroid gland.

ing sepsis, mediastinitis, acute pancreatitis, or intestinal perforation, one was in a severe condition after drowning, and one had status epilepticus.

\section{Comparison between ECLIA-CT and RIA-CT}

ECLIA-CTs ranged from $<0.500 \mathrm{pg} / \mathrm{mL}$ to 9,936 $\mathrm{pg} / \mathrm{mL}$ (Table 2). The median was $<0.500 \mathrm{pg} / \mathrm{mL}$, and $63 \%$ of all samples were $<0.500 \mathrm{pg} / \mathrm{mL}$. RIA-CT ranged from $15 \mathrm{pg} / \mathrm{mL}$ to $14,133 \mathrm{pg} / \mathrm{mL}$, and the median was $34 \mathrm{pg} / \mathrm{mL}$. The median $\mathrm{CT}$ in the females was significantly lower than that in the males in both ECLIA ( $p<$ $0.001)$ and RIA $(p=0.017)$. Similar differences in ECLIA-CT and RIA-CT between males and females were observed in the non-MTC patients.

As shown in Fig. 1A, there was a significant correlation (Spearman's rank correlation coefficient $\left[r_{\mathrm{s}}\right]=$ 0.373, $p<0.001$ ) between ECLIA-CT and RIA-CT in all 348 samples. When the samples with CT $>150 \mathrm{pg} / \mathrm{mL}$ measured by ECLIA and RIA were analyzed $(N=11)$, this correlation was strengthened $\left(r_{\mathrm{s}}=0.991, p<0.001\right)$. In contrast, when these 11 samples were excluded $(N=$ $337)$, the correlation was weakened $\left(r_{\mathrm{s}}=0.299, p<\right.$ 0.001) (Fig. 1B). There were 19 patients whose CT concentrations were undetectable by ECLIA but were above the reference range when RIA was used. In these 
Table 2 Serum calcitonin concentrations measured by ECLIA and RIA

\begin{tabular}{|c|c|c|c|c|c|c|c|c|}
\hline & & & Minimum & $25^{\text {th }}$ & Median & $75^{\text {th }}$ & Maximum & $p^{*}$ \\
\hline \multirow{6}{*}{$\begin{array}{c}\text { All } \\
N=348\end{array}$} & \multirow{3}{*}{ ECLIA-CT (pg/mL) } & Total & $<0.500$ & $<0.500$ & $<0.500$ & 1.014 & $9,936.0$ & \\
\hline & & Male & $<0.500$ & $<0.500$ & 1.490 & 4.115 & 818.6 & \multirow{2}{*}{$<0.001$} \\
\hline & & Female & $<0.500$ & $<0.500$ & $<0.500$ & $<0.500$ & $9,936.0$ & \\
\hline & \multirow{3}{*}{ RIA-CT (pg/mL) } & Total & 15.0 & 28.0 & 34.0 & 43.0 & $14,133.0$ & \\
\hline & & Male & 16.0 & 29.8 & 36.5 & 47.8 & $1,153.0$ & \multirow{2}{*}{0.017} \\
\hline & & Female & 15.0 & 27.0 & 33.0 & 42.0 & $14,133.0$ & \\
\hline \multirow{6}{*}{$\begin{array}{c}\text { non-MTC } \\
N=333\end{array}$} & \multirow{3}{*}{ ECLIA-CT (pg/mL) } & Total & $<0.500$ & $<0.500$ & $<0.500$ & 0.892 & 818.6 & \\
\hline & & Male & $<0.500$ & $<0.500$ & 1.420 & 4.015 & 818.6 & \multirow{2}{*}{$<0.001$} \\
\hline & & Female & $<0.500$ & $<0.500$ & $<0.500$ & $<0.500$ & 3.620 & \\
\hline & \multirow{3}{*}{ RIA-CT (pg/mL) } & Total & 15.0 & 27.0 & 33.0 & 41.0 & $1,153.0$ & \\
\hline & & Male & 16.0 & 29.8 & 36.0 & 46.0 & $1,153.0$ & \multirow{2}{*}{0.006} \\
\hline & & Female & 15.0 & 27.0 & 33.0 & 39.0 & 152.0 & \\
\hline
\end{tabular}

CT values are presented as median, lower and upper quartiles, minimum, and maximum.

The CT values below the measurement range of ECLIA were calculated as $0.500 \mathrm{pg} / \mathrm{mL}$.

$N$, number; MTC, medullary thyroid carcinoma

* Mann-Whitney $U$ test.

A

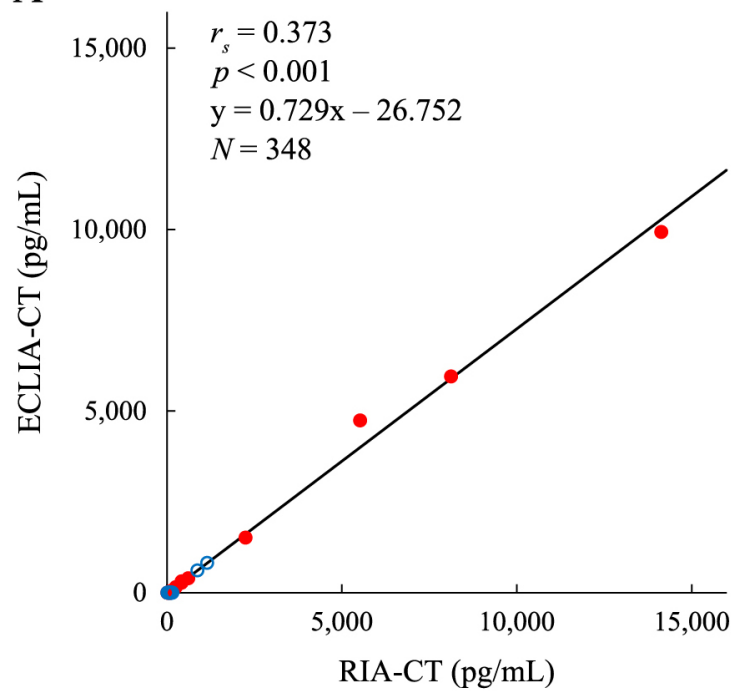

B

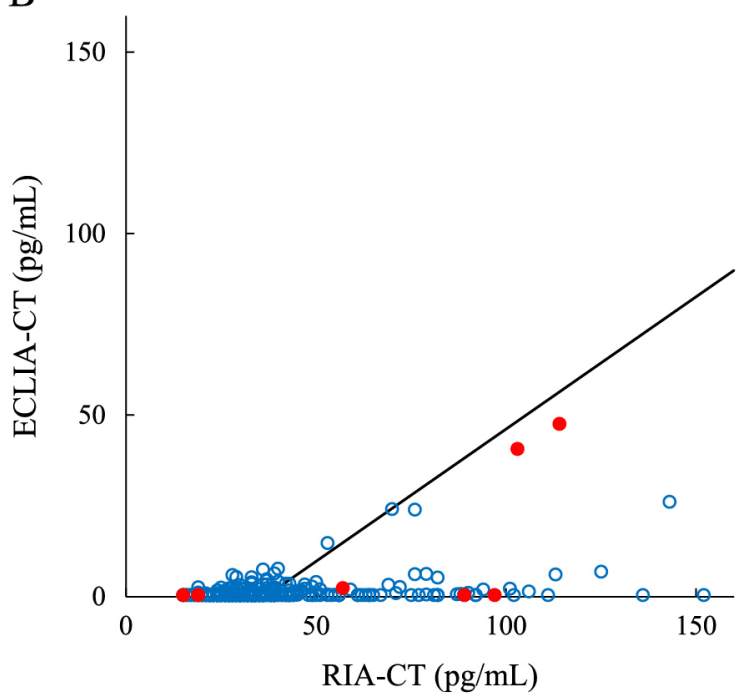

Fig. 1 The correlation between ECLIA-CT and RIA-CT

A: All 348 samples are shown. B: 337 samples after exclusion of 11 samples with CT >150 pg/mL by both ECLIA and RIA are shown. Red closed circles and blue open circles represent MTC and non-MTC, respectively. The regression lines were calculated with data of all 348 samples according to standard major axis regression. $r_{\mathrm{s}}$ represents Spearman's rank correlation coefficient.

patients, there were four patients with extra-thyroid malignancy (liposarcoma, breast cancer, and uterine cervical cancer), four patients with post-total thyroidectomy for non-MTC, and one MTC patient with post-total thyroidectomy and without metastasis.

The histogram of CT values of 25 samples from patients after total thyroidectomy for non-MTC is shown in Fig. 2. In 24 of the 25 samples, ECLIA-CTs were
$<0.500 \mathrm{pg} / \mathrm{mL}$. On the other hand, RIA-CTs ranged widely from $16 \mathrm{pg} / \mathrm{mL}$ to $152 \mathrm{pg} / \mathrm{mL}$, though they tended to be low. The difference between ECLIA-CT and RIA$\mathrm{CT}$ in the thyroidectomized patients may imply a crossreactivity of RIA.

\section{High ECLIA-CT cases without MTC}

There were 15 patients without MTC whose ECLIA- 


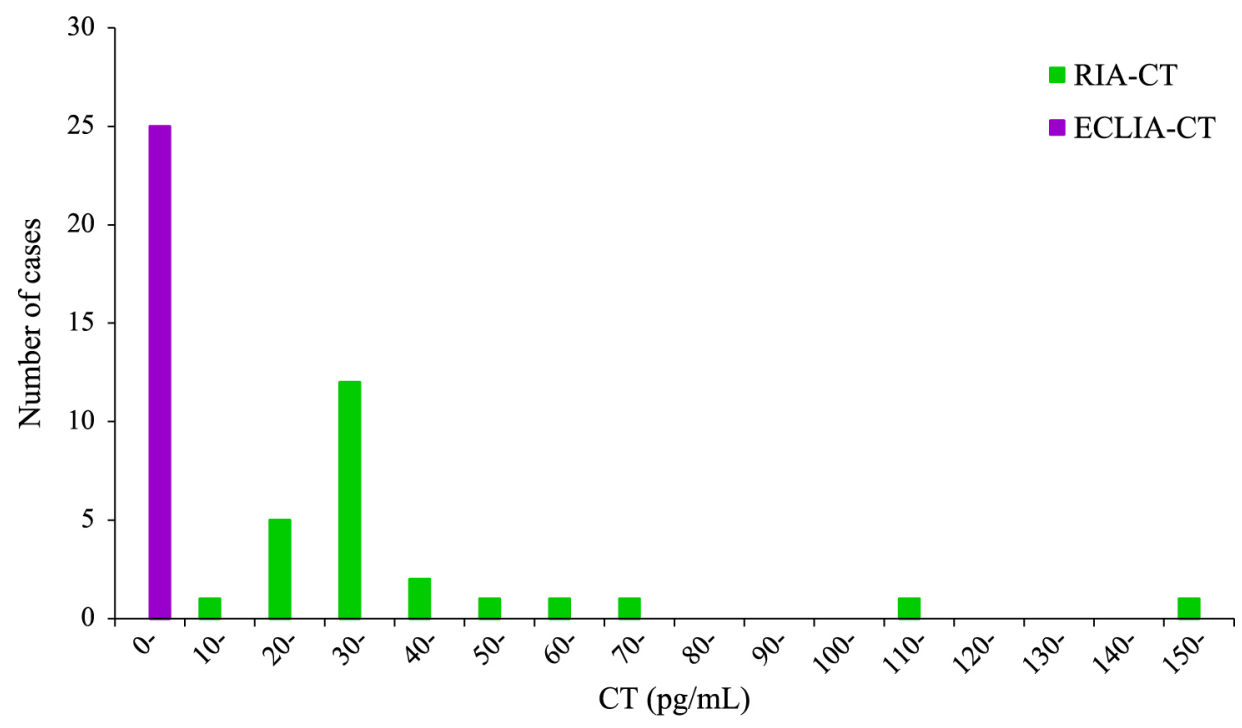

Fig. 2 Histogram of RIA-CT and ECLIA-CT of 25 samples after total thyroidectomy for non-MTC

Green bars and purple bar show the number of samples in each CT level category measured by RIA and ECLIA, respectively. ECLIA method revealed that the CT level of one sample was $1.140 \mathrm{pg} / \mathrm{mL}$ and those of the other 24 samples were $<0.500 \mathrm{pg} / \mathrm{mL}$.

CTs were greater than the reference range (Table 3). There were two instances where multiple samples from a single patient had similar values (Cases 1 and 10). The highest ECLIA-CT was $818.6 \mathrm{pg} / \mathrm{mL}$ in Case 1 with a pancreatic neuroendocrine tumor (PNET), ECLIA-CTs in the remaining 14 patients did not exceed $30 \mathrm{pg} / \mathrm{mL}$. Among the 15 patients, four had chronic renal failure (Cases 2, 8, 10 and 11) whose RIA-CTs also tended to be increased, five patients had extra-thyroid malignancies (Cases 1, 3, 7, 14 and 15). Concerning thyroid disease, one patient had PTC, three had benign nodules including AFTN, and two patients had GD.

\section{MTC cases}

Nine patients had MTC, three men and six women (Table 4). Among them, only one (Case 8) had not yet undergone surgery, and her CT levels by both ECLIA and RIA were significantly increased to $1,516 \mathrm{pg} / \mathrm{mL}$ and 2,246 pg/mL, respectively. In another case after total thyroidectomy (Case 5), ECLIA-CTs were undetectable, in spite of RIA-CTs higher than the reference range. In Case 5, RIA-CTs before and ECLIA-CTs after the period of collecting serum samples for this study showed no tendency to increase; furthermore, no recurrence or metastasis had been found by either ultrasonography or computerized tomography.

\section{Relations between ECLIA-CT and clinical factors}

The relationships between ECLIA-CT and the available clinical data were investigated in 273 samples after the exclusion of samples from patients with MTC or PNET, as well as those from patients who had undergone total or partial thyroidectomy (Table 5). There were no correlations between ECLIA-CT and TRAb, intact-PTH, or calcium concentration.

Regarding $\mathrm{TgAb}$ and TPOAb, however, there were negative correlations between ECLIA-CT and those titers ( $p=0.005$ and $p=0.015$, respectively). In addition, a significant difference was observed in ECLIA-CT between the $\operatorname{TgAb}$ positive and negative samples ( $p=$ 0.002 ). The same was observed between TPOAb positive and negative samples $(p=0.009)$. In the logistic regression analysis, $\mathrm{TgAb}$ and TPOAb were significantly associated with ECLIA-CT ( $p=0.004$ and 0.014 , respectively). After exclusion of the TgAb-positive samples, there was a negative correlation between ECLIA-CT and thyroglobulin $(p=0.021)$. Logistic regression analysis showed no significant association with ECLIA-CT ( $p=$ 0.244).

Between ECLIA-CT and eGFR, there was a negative correlation $(p=0.019)$. After categorization into four groups according to CKD stage, ECLIA-CTs in the eGFR $<30 \mathrm{~mL} / \mathrm{min} / 1.73 \mathrm{~m}^{2}$ group were higher than those of the other three groups $(p<0.001)$. In the logistic regression analysis, the association with ECLIA-CT was statistically significant ( $p=0.008)$.

Of the 273 patients, 271 were divided into two categories: clinically diagnosed with or without extra-thyroid malignancy. ECLIA-CTs did not significantly differ between the two groups. Among 26 cases with extrathyroid malignancy, ECLIA-CTs were higher than the reference range in four patients: hypopharyngeal cancer (squamous cell carcinoma); lung cancer (squamous cell carcinoma); prostate cancer; and malignant lymphoma 
Table 3 Clinical information of non-MTC patients with high ECLIA-CT

\begin{tabular}{|c|c|c|c|c|c|}
\hline Case & Sex/Age & Thyroid disease & Extra-thyroid diseases & $\begin{array}{l}\text { ECLIA-CT } \\
(\mathrm{pg} / \mathrm{mL})\end{array}$ & $\begin{array}{c}\text { RIA-CT* } \\
(\mathrm{pg} / \mathrm{mL})\end{array}$ \\
\hline 1 & $\mathrm{M} / 47$ & Normal thyroid & $\begin{array}{l}\text { MEN1 (PNET, Prolactinoma, Operated } \\
\text { pheochromocytoma, Operated PH) }\end{array}$ & $\begin{array}{l}\# 1: 818.6 \\
\# 2: 610.5 \\
\# 3: 572.4\end{array}$ & $\begin{array}{l}\# 1: \underline{1,153} \\
\# 2: \underline{870} \\
\# 3: \underline{1,075}\end{array}$ \\
\hline 2 & $\mathrm{M} / 48$ & Normal thyroid & CRF (HD), Operated SH & 26.13 & $\underline{143}$ \\
\hline 3 & $\mathrm{M} / 40$ & PTC & Lung cancer (SCC) & 24.17 & 70 \\
\hline 4 & $\mathrm{M} / 35$ & Benign nodule & MEN2 (Operated pheochromocytoma) & 24.00 & 76 \\
\hline 5 & $\mathrm{M} / 27$ & Unknown & Pseudohypoparathyroidism & 14.81 & 53 \\
\hline 6 & $\mathrm{M} / 28$ & AFTN & None & 7.72 & 40 \\
\hline 7 & $\mathrm{M} / 56$ & Invasion & Hypopharyngeal cancer & 7.51 & 36 \\
\hline 8 & $\mathrm{M} / 58$ & Unknown & CRF (HD), Epilepsy, Inflammation of unknown lesion & 6.94 & $\underline{125}$ \\
\hline 9 & $\mathrm{M} / 67$ & GD & None & 6.43 & 39 \\
\hline 10 & $\mathrm{M} / 61$ & Cyst & CRF (HD), SH & $\begin{array}{l}\# 1: 6.26 \\
\# 2: 6.21\end{array}$ & $\begin{array}{l}\# 1: 79 \\
\# 2: 76\end{array}$ \\
\hline 11 & $\mathrm{M} / 77$ & Unknown & $\begin{array}{l}\text { Acute worsening of CRF, Sepsis caused by acute } \\
\text { suppurative cholangitis and pancreatitis, Retroperitoneal } \\
\text { fibrosis }\end{array}$ & 6.15 & $\underline{113}$ \\
\hline 12 & $\mathrm{M} / 40$ & GD & None & 6.00 & 28 \\
\hline 13 & $\mathrm{M} / 63$ & Benign nodule & Operated skin cancer (SCC) & 5.48 & 29 \\
\hline 14 & $\mathrm{M} / 72$ & Cyst & Prostate cancer & 5.36 & 33 \\
\hline 15 & $\mathrm{M} / 68$ & Unknown & $\begin{array}{l}\text { Malignant lymphoma, Gastric cancer, Colon cancer, } \\
\text { Peritonitis }\end{array}$ & 5.28 & 82 \\
\hline
\end{tabular}

M, male; PNET, pancreas neuroendocrine tumor; CRF, chronic renal failure; HD, hemolytic dialysis; SCC, squamous cell carcinoma; PH, primary hyperparathyroidism; $\mathrm{SH}$, secondary hyperparathyroidism

In cases that provided multiple samples, CT value of each sample is shown.

* The underlined CT values are above the reference range of RIA-CT.

coexisting with gastric cancer (tubular adenocarcinoma) and colon cancer (mucinous carcinoma) (Supplementary Table 2). ECLIA-CTs in these four patients were $7.51 \mathrm{pg} / \mathrm{mL}, 24.17 \mathrm{pg} / \mathrm{mL}, 5.36 \mathrm{pg} / \mathrm{mL}$, and $5.28 \mathrm{pg} / \mathrm{mL}$, respectively (Table 3 ).

After multivariate logistic regression analysis with four variables (sex, TgAb, TPOAb, and eGFR), only three variables (male sex, negative $\mathrm{TgAb}$, and lower eGFR) were shown to be independent factors for predicting whether ECLIA-CT was detectable or undetectable (Table 6). Among the three independent predictors, sex had the strongest effect on ECLIA-CT $(\mathrm{OR}=12.228$, $p<0.001$ ).

\section{Discussion}

In the current study, we found a significant correlation between ECLIA-CT and RIA-CT. However, this correlation was weakened when the samples with $\mathrm{CT}$ $>150 \mathrm{pg} / \mathrm{mL}$ measured by ECLIA and RIA were exclud- ed, showing discordance between the two assays. We observed increased RIA-CTs in some of non-MTC cases with post-total thyroidectomy despite undetectable ECLIA-CTs. Further, we demonstrated that ECLIA-CTs were higher than the reference range in some cases with non-MTC.

Kratzsch et al. compared CT concentrations by two chemiluminescent immunometric fully automated assays and an immunoradiometric assay (IRMA), and reported that the use of IRMA led to increased CT concentrations in the sera of thyroidectomized patients, and showed cross-reactivity with ProCT in patients with concomitant bacterial infection [12]. Kaczka et al. evaluated ProCT utility as a marker of MTC [13], and reported elevated CT levels measured using one-step sandwich chemiluminescence immunoassay in 10 of 20 patients with elevated ProCT who had severe bacterial infection or sepsis. In the present study, among the patients with increased CT, there were some patients who were undergoing treatment for systemic inflammatory disorders or sepsis, in which 
Table 4 Clinical information on patients with MTC

\begin{tabular}{|c|c|c|c|c|c|}
\hline Case & Sex/Age & Surgery & Extra-thyroid disease & ECLIA-CT* $(\mathrm{pg} / \mathrm{mL})$ & RIA-CT* $(\mathrm{pg} / \mathrm{mL})$ \\
\hline \multirow{2}{*}{1} & \multirow{2}{*}{$\mathrm{M} / 48$} & \multirow{2}{*}{ Post-TT } & \multirow{2}{*}{ MEN2 (Operated pheochromocytoma) } & $\# 1: \underline{47.63}$ & $\# 1: 114$ \\
\hline & & & & $\# 2: \underline{40.71}$ & $\# 2: 103$ \\
\hline \multirow{3}{*}{2} & \multirow{3}{*}{$\mathrm{F} / 41$} & \multirow{3}{*}{ Post-TT } & \multirow{3}{*}{$\begin{array}{l}\text { MEN2 (Operated pheochromocytoma), Operated } \\
\text { appendiceal cancer }\end{array}$} & $\# 1: \underline{5,960}$ & $\# 1: \underline{8,119}$ \\
\hline & & & & $\# 2: \overline{9,936}$ & $\# 2: \overline{14,133}$ \\
\hline & & & & $\# 3: \underline{4,748}$ & $\# 3: \underline{5,522}$ \\
\hline 3 & $\mathrm{M} / 52$ & Post-TT & MEN2 (Operated pheochromocytoma, Operated PH) & $<0.500$ & 19 \\
\hline 4 & $\mathrm{M} / 57$ & Post-TT & None & 2.36 & 57 \\
\hline \multirow{2}{*}{5} & \multirow{2}{*}{$\mathrm{F} / 63$} & \multirow{2}{*}{ Post-TT } & \multirow{2}{*}{ MEN2 (Operated pheochromocytoma) } & $\# 1:<0.500$ & $\# 1: \underline{89}$ \\
\hline & & & & $\# 2:<0.500$ & $\# 2: \underline{97}$ \\
\hline \multirow{3}{*}{6} & \multirow{3}{*}{$\mathrm{F} / 73$} & \multirow{3}{*}{ Post-lobectomy } & \multirow{3}{*}{ None } & $\# 1: \underline{277.8}$ & $\# 1: \underline{416}$ \\
\hline & & & & $\# 2: \underline{318.0}$ & $\# 2: \underline{418}$ \\
\hline & & & & $\# 3: \underline{395.4}$ & $\# 3: \underline{613}$ \\
\hline 7 & $F / 29$ & Post-TT & MEN2 (Operated pheochromocytoma) & $\underline{150.4}$ & $\underline{251}$ \\
\hline 8 & $\mathrm{~F} / 56$ & Preoperative & Dermatomyositis, Interstitial pneumonia & $\underline{1,516}$ & $\underline{2,246}$ \\
\hline 9 & $F / 29$ & Post-TT & MEN2 (Operated pheochromocytoma) & $<0.500$ & 15 \\
\hline
\end{tabular}

$\mathrm{M}$, male; F, female; TT, total thyroidectomy; $\mathrm{PH}$, primary hyperparathyroidism

In cases that provided multiple samples, $\mathrm{CT}$ value of each sample is shown.

* The underlined CT values are above the reference ranges.

cases CT-precursor peptides as well as ProCT would be increased. In seven patients with elevated ProCT, while RIA-CTs were higher than the reference range in five cases (not shown), ECLIA-CTs were slightly higher in three cases (Cases 8, 11 and 15, Table 3). These results indicate that the variation in cross-reactivity with these precursors by each assay affected the CT level. The RIA employed in this study provided no information on crossreactivity between $\mathrm{CT}$ and ProCT. In contrast, it has been reported that ECLIA-CT did not cross-react with ProCT [14]. Nevertheless, it is possible that cross-reactivity with other CT-precursor peptides might have been involved in the elevation of ECLIA-CT in cases with high ProCT in the present study.

On the other hand, the CT concentrations in our patients who had undergone total thyroidectomy for nonMTC varied widely when measured using RIA, but were mostly undetectable by ECLIA. The difference between ECLIA-CT and RIA-CT in the thyroidectomized patients of the present study may imply that RIA incorrectly detects antigens as CT. Whereas polyclonal antibodies are used in the RIA method, the ECLIA system, to which sandwich immunoassays are applied, uses monoclonal antibodies for the recognition of CT. Seth et al. reported that lower CT levels of a two-site enzyme-immunoassay using monoclonal antibodies compared to the levels of RIA employing a polyclonal antiserum were presumably due to the ability to detect only the 'mature' form of CT [15]. Motte et al. compared a two-site monoclonal IRMA and a conventional polyclonal RIA, and reported that monoclonal anti-CT antibodies provided a definitive specificity for the mature form of the circulating CT [16]. These findings of these studies support the speculation that the ECLIA method surpassed the RIA method in detecting human CT itself specifically.

It was previously reported that serum CT levels would be increased in patients with chronic renal failure, and other ailments, such as hypercalcemia, autoimmune thyroiditis, small cell and large cell lung cancers, prostate cancer, mastocytosis, and various enteric and pulmonary neuroendocrine tumors [8]. Kahaly et al. recently published a multicenter prospective study on serum CT measured by ECLIA in 1,929 patients and healthy controls [14]. They reported that patients with renal failure (14\% of 57 patients), primary hyperparathyroidism (10.9\% of 55$)$, neuroendocrine tumors $(10.2 \%$ of 49$)$, GD (4.5\% of 111$)$, and benign nodules $(2.1 \%$ of 375$)$, as well as controls ( $2.3 \%$ of 783 controls) had serum CT concentrations above the $97.5^{\text {th }}$ percentile. In the present study, ECLIA-CTs in $4.5 \%$ of all 334 patients were above the reference range, which was determined by the 97.5th percentile of healthy controls [9]. This high ECLIA-CT was observed not only in patients with MTC, but also in those with non-MTC, including PNET, chronic renal failure, extra-thyroid malignancies, and GD. These results are largely consistent with those of a previous study by Kahaly et al.

For multivariate logistic analysis, we set up two 
Table 5 Relationships between ECLIA-CT and each sex, thyroid autoantibodies, thyroglobulin, calcium, intact-PTH, eGFR, extra-thyroid malignancy, thyroid nodular lesion, and thyroid residual volume

\begin{tabular}{|c|c|c|c|c|c|c|c|c|c|c|c|c|c|}
\hline & \multirow{2}{*}{$N$} & \multicolumn{2}{|c|}{ Correlation } & \multirow{2}{*}{ Category } & \multirow{2}{*}{$N$} & \multicolumn{4}{|c|}{ ECLIA-CT (pg/mL) } & \multirow{2}{*}{$p^{*}$} & \multicolumn{3}{|c|}{ Logistic regression** } \\
\hline & & $r_{\mathrm{s}}$ & $p$ & & & 25 th & 50th & 75th & 90th & & OR & $95 \% \mathrm{CI}$ & $p$ \\
\hline \multirow{2}{*}{ Sex $* * *$} & \multirow{2}{*}{273} & & & Female & 201 & $<0.500$ & $<0.500$ & $<0.500$ & 1.134 & \multirow{2}{*}{$<0.001$} & \multirow{2}{*}{12.112} & \multirow{2}{*}{$6.294-23.311$} & \multirow{2}{*}{$<0.001$} \\
\hline & & & & Male & 72 & 0.701 & 1.775 & 3.893 & 6.787 & & & & \\
\hline \multirow{2}{*}{$\operatorname{TRAb}(\mathrm{IU} / \mathrm{L}) * * *$} & \multirow{2}{*}{273} & \multirow{2}{*}{0.068} & \multirow{2}{*}{0.263} & $<2.0$ & 222 & $<0.500$ & $<0.500$ & 1.070 & 3.338 & \multirow{2}{*}{0.963} & \multirow{2}{*}{1.040} & \multirow{2}{*}{$0.557-1.941$} & \multirow{2}{*}{0.902} \\
\hline & & & & $\geq 2.0$ & 51 & $<0.500$ & $<0.500$ & 0.968 & 2.688 & & & & \\
\hline \multirow{2}{*}{$\operatorname{TgAb}(\mathrm{IU} / \mathrm{mL})^{* * *}$} & \multirow{2}{*}{273} & 0160 & 0005 & $<28.0$ & 179 & $<0.500$ & $<0.500$ & 1.510 & 3.600 & $000 ?$ & 0440 & 00200772 & 0004 \\
\hline & & -0.169 & 0.005 & $\geq 28.0$ & 94 & $<0.500$ & $<0.500$ & 0.583 & 1.795 & 0.002 & 0.448 & $0.260-0.1 / 3$ & 0.004 \\
\hline TPOAh(II/mI)*** & 273 & 0147 & 0015 & $<16.0$ & 159 & $<0.500$ & $<0.500$ & 1.510 & 3.620 & 0000 & 0.527 & $0317-0876$ & 0014 \\
\hline 1PUAD $(1 \mathrm{IU} / \mathrm{mL})^{*}$ & $2 / 3$ & $-0.14 /$ & 0.015 & $\geq 16.0$ & 114 & $<0.500$ & $<0.500$ & 0.726 & 2.070 & 0.009 & 0.521 & $0.31 /-0.8 / 6$ & 0.014 \\
\hline & & & & Q1 (<8.08) & & $<0.500$ & $<0.500$ & 2.013 & 3.513 & & & & \\
\hline$T \rho(n-m I) * * *$ & & 0017 & 0.784 & Q2 ( $\geq 8.08,<25.83)$ & & $<0.500$ & $<0.500$ & 0.935 & 5.547 & 0523 & 0000 & 00041242 & 0002 \\
\hline 1द (IIg) & 215 & -0.011 & 0.184 & Q3 $(\geq 25.83,<94.91)$ & & $<0.500$ & $<0.500$ & 0.704 & 1.463 & 0.523 & 0.999 & $0.804-1.242$ & 0.993 \\
\hline & & & & Q4 ( $\geq 94.91)$ & & $<0.500$ & $<0.500$ & 1.490 & 3.240 & & & & \\
\hline & & & & Q1 $(<10.71)$ & & $<0.500$ & 1.320 & 2.550 & 6.150 & & & & \\
\hline $\mathrm{Tg}(\mathrm{ng} / \mathrm{mL})$ in & & & (0001 & Q2 $(\geq 10.71,<28.62)$ & & $<0.500$ & $<0.500$ & 0.785 & 5.748 & 0010 & 0050 & 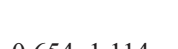 & 0020 \\
\hline $\begin{array}{l}\text { samples } \\
\text { sav-litur }\end{array}$ & 179 & $-0.1 / 2$ & 0.021 & Q3 $(\geq 28.62,<94.91)$ & & $<0.500$ & $<0.500$ & 0.763 & 1.578 & 0.010 & 0.854 & $0.654-1.114$ & 0.244 \\
\hline & & & & Q4 ( $\geq 94.91)$ & & $<0.500$ & $<0.500$ & 1.695 & 3.808 & & & & \\
\hline & & & & Q1 $(<9.3)$ & & $<0.500$ & $<0.500$ & 1.650 & 6.997 & & & & \\
\hline$C_{0}(m)$ & 89 & 0018 & 0872 & Q2 $(\geq 9.3,<9.5)$ & & $<0.500$ & 0.565 & 2.055 & 4.117 & 0005 & 1005 & 06801464 & 0091 \\
\hline (a (III) UL) & 02 & -0.010 & 0.015 & Q3 $(\geq 9.5,<9.7)$ & & $<0.500$ & $<0.500$ & 1.375 & 5.998 & 0.993 & 1.005 & $0.689-1.464$ & 0.981 \\
\hline & & & & $\mathrm{Q} 4(\geq 9.7)$ & & $<0.500$ & $<0.500$ & 1.400 & 5.415 & & & & \\
\hline & & & & Q1 $(<35.02)$ & & $<0.500$ & 0.756 & 1.415 & 23.669 & & & & \\
\hline Intact-PTH & 12 & & $0-657$ & Q2 ( $\geq 35.02,<50.79)$ & & $<0.500$ & $<0.500$ & 1.530 & 2.416 & 725 & ר?70 & & \\
\hline$(\mathrm{pg} / \mathrm{mL})^{* * * *}$ & 43 & -0.092 & 0.557 & Q3 $(\geq 50.79,<75.68)$ & & $<0.500$ & 0.738 & 1.510 & 20.018 & 0.725 & 0.722 & $0.413-1.261$ & 0.252 \\
\hline & & & & Q4 ( $\geq 75.68)$ & & $<0.500$ & $<0.500$ & 3.350 & 13.090 & & & & \\
\hline & & & & $<30$ & 9 & 1.245 & 2.220 & 6.575 & - & & & & \\
\hline eGFR $(\mathrm{mL} / \mathrm{min} /$ & 122 & 4 & 0010 & $\geq 30,<60$ & 24 & $<0.500$ & $<0.500$ & 0.707 & 2.220 & $<0001$ & 0512 & 02140052 & 0008 \\
\hline $\left.1.73 \mathrm{~m}^{2}\right)^{*}$ & 133 & -0.204 & 0.019 & $\geq 60,<90$ & 70 & $<0.500$ & $<0.500$ & 0.627 & 3.586 & $<0.001$ & 0.342 & $0.344-0.852$ & 0.008 \\
\hline & & & & $\geq 90$ & 30 & $<0.500$ & $<0.500$ & 1.068 & 2.583 & & & & \\
\hline Extra-thyroid & 271 & & & No & 245 & $<0.500$ & $<0.500$ & 1.007 & 2.628 & 0.044 & 0850 & $0364-1086$ & 0708 \\
\hline malignancy $* * * * *$ & 211 & & & Yes & 26 & $<0.500$ & $<0.500$ & 1.540 & 6.005 & 0.944 & 0.850 & $0.364-1.986$ & 0.108 \\
\hline & & & & PTC or FTC & 36 & $<0.500$ & $<0.500$ & 1.215 & 2.970 & & & & \\
\hline $\begin{array}{l}\text { Thyroid nodular } \\
\text { lesion****** }\end{array}$ & 260 & & & FA or Benign nodule & 127 & $<0.500$ & $<0.500$ & 0.758 & 2.032 & 0.570 & 1.035 & $0.712-1.506$ & 0.857 \\
\hline & & & & No nodule & 97 & $<0.500$ & $<0.500$ & 1.059 & 3.254 & & & & \\
\hline & & & & Total thyroidectomy & 25 & $<0.500$ & $<0.500$ & $<0.500$ & $<0.500$ & & & & \\
\hline Thyroid residual & 324 & & & Partial thyroidectomy & 26 & $<0.500$ & $<0.500$ & $<0.500$ & 0.748 & $<0.001$ & 3.259 & $1.648-6.447$ & 0.001 \\
\hline & & & & No thyroidectomy & 273 & $<0.500$ & $<0.500$ & 1.045 & 2.724 & & & & \\
\hline
\end{tabular}

$r_{\mathrm{s}}$, Spearman's rank correlation coefficient; $N$, number; OR, odds ratio; CI, confidence intervals; Tg, thyroglobulin; PTC, papillary thyroid carcinoma; FTC, follicular thyroid carcinoma; FA, follicular adenoma

* Mann-Whitney $U$ tests were used for sex, TRAb, TgAb, TPOAb, or Extra-thyroid malignancy. Kruskall-Wallis tests were used for the others. ** Logistic regression analysis was performed with categorical values of clinical and laboratory findings. TRAb, TgAb, TPOAb were categorized into two groups, positive or negative. Thyroglobulin, intact-PTH and serum calcium were categorized into four groups quarterly. eGFR was classified into four groups based on GFR categories. Objective variable of this analysis was CT levels categorized into two groups, undetectable or detectable. *** Among 334 patients, 61 with MTC, PNET or after total or partial thyroidectomy were excluded from the analyses $(N=273)$. **** Samples with available data of Ca ( 82 cases), intact-PTH ( 43 cases) or eGFR ( 133 cases) were included. ***** Of the 273 cases, two samples without any information about extra-thyroid disease were excluded from the analysis $(N=271)$. ****** Among the 273 cases, 13 cases of cyst group or unknown group were excluded from the analysis $(N=260)$. ******* Among the total 334 cases, 10 cases of MTC or PNET were excluded from the analyses $(N=324)$. 
Table 6 The result of multivariate logistic regression analysis

\begin{tabular}{lccc}
\hline & \multicolumn{1}{c}{ OR } & \multicolumn{1}{c}{$95 \%$ CI } & $p$ \\
\hline Sex (male) & 12.228 & $4.726-31.639$ & $<0.001$ \\
TgAb (positive) & 0.378 & $0.152-0.940$ & 0.036 \\
eGFR (+1 stage) & 0.544 & $0.316-0.936$ & 0.028 \\
\hline
\end{tabular}

OR, odds ratio; $\mathrm{CI}$, confidence intervals

Multivariate logistic regression analysis was performed with categorical values of clinical and laboratory findings. Among the total 334 patients, 61 cases with MTC, PNET or after total or partial thyroidectomy were excluded from the analyses. Forward stepwise selection was adopted in this analysis with four variables that had significant associations with ECLIA-CT in Table 5: TgAb and TPOAb were categorized into two groups, positive or negative. eGFR was classified into four groups based on GFR categories. Objective variable of this analysis was CT levels categorized into two groups, undetectable or detectable.

categories for ECLIA-CT, $<0.500 \mathrm{pg} / \mathrm{mL}$ and $\geq 0.500$ $\mathrm{pg} / \mathrm{mL}$, because ECLIA-CTs were below the analytical sensitivity in $65 \%$ of the 334 patients and there were only 15 males whose ECLIA-CTs were higher than the reference range. As a result, male sex, negative $\mathrm{TgAb}$, and lower eGFR were determined to be independent predictors for detectable ECLIA-CT.

There have been several reports describing the difference in CT levels between men and women, measured by non-RIA methods $[17,18]$. Some studies on ECLIA have also revealed that the reference $\mathrm{CT}$ intervals in men and women were different; CT levels were higher in men than in women $[9,14]$. The results of the present study regarding this are in accordance with those of previous studies. Guyetant et al. reported that C-cell density in men was more than twice that in women [19], which was considered to be one of the reasons for the higher $\mathrm{CT}$ concentrations in men.

Concerning renal function, among the four eGFR groups we made for comparison, ECLIA-CTs in the eGFR $<30 \mathrm{~mL} / \mathrm{min} / 1.73 \mathrm{~m}^{2}$ group were statistically higher than those in the other three groups. Lissak et al. also reported that basal mature $\mathrm{CT}$ on a pentagastrin test was significantly higher in patients with chronic renal failure than in controls [20]. On the other hand, Kratzsch et al. reported that no correlation was found between CKD stage and CT concentration determined by two chemiluminescent immunometric fully automated assays [12]. However, there have been some reports, published before the development of ICMA, that referred to the reason for elevated $\mathrm{CT}$ in chronic renal failure. Simmons et al. reported that kidney played an important role in the metabolism of CT [21]. Renal disease is often associated with increased serum immunoreactive CT levels, most of which consist of CT-precursor peptides [22]. As mentioned above, the present study included seven cases with elevated ProCT, three of which were categorized into the eGFR $<30 \mathrm{~mL} / \mathrm{min} / 1.73 \mathrm{~m}^{2}$ group. Therefore, it was difficult to determine the factor of statistical difference among CT levels in the four eGFR groups, namely chronic renal failure or cross-reactivity with ProCT. In renal dysfunction, it is likely that CT level would be influenced by another factor, such as phosphate, calcium, and parathyroid hormone, directly or indirectly. Silva et al. reported that CT levels correlated inversely with serum calcium in patients on dialysis and directly with serum calcium in non-dialysis patients [23]. In the present study, statistical analyses showed no relationship between ECLIA-CT and intact-PTH concentration, or between ECLIA-CT and serum calcium level. These results suggest that ECLIA-CT would be increased in a non-MTC patient with renal failure, although the mechanism for this remains unclear.

The association between thyroiditis and hypercalcitoninemia is still controversial $[24,25]$. In the present study, ECLIA-CTs were higher than the reference range in two of the 62 patients with GD, and there was no patient with HT whose ECLIA-CT level was higher than the reference range. TPOAb was negatively associated with ECLIA-CT, but the relationship was not found to be significant by multivariate logistic analysis. Grani et al. previously reported a similar result that basal CT, measured by automated two-site immunochemiluminometric assay, was not significantly higher in patients who were TPOAb-positve [26]. With regard to TgAb, however, the current study revealed a significant association between ECLIA-CT and TgAb titer; ECLIA-CTs were statistically lower in the $\operatorname{TgAb}$ positive group than in the $\operatorname{TgAb}$ negative group. $\operatorname{TgAb}$ is widely known to be associated with autoimmune thyroiditis, and was also reported to be associated with PTC [27, 28]. While Toledo et al. stated in their review that HT and PTC were two of the causes of CT elevation [29], Rosario et al. reported no difference in CT levels or frequency of elevated CT between patients with and without HT, and those with and without PTC $>1 \mathrm{~cm}$ [30]. In certain situations, such as when heterophilic antibody is present, CT level could be elevated in patients without MTC [31]. The negative relationship between ECLIA-CT and TgAb in the present study suggested that CT level might be affected by HT. It has been reported that interference in measurement by antibodies or influence to C-cell by histological changes of thyroid gland induced by HT were possible mechanisms of the relationship [32-35].

Among 26 cases clinically diagnosed with extrathyroid malignancy, increased ECLIA-CTs were found in four patients with hypopharyngeal cancer, lung cancer, prostate cancer, or malignant lymphoma coexisting with gastric and colon cancer. It was reported that CT concen- 
tration was increased in patients with small cell lung cancer [36], large cell lung cancer with neuroendocrine differentiation [37], or small cell carcinoma of the prostate [38]. In these cases, it was considered that increased CT levels were induced by ectopic secretion. The pathological diagnoses of the cancers in the patients with higher ECLIA-CTs than the reference range in the present study were different from those in previous reports, though the invaded organs were similar. This suggests that the slight increase of CT levels in our cases might be nonspecific, such as cross-reactivity with nonCT polypeptide.

In the present study, we could not obtain a large enough number of samples from preoperative MTC patients to determine a cutoff $\mathrm{CT}$ level for diagnosis of MTC. Alternatively, we assessed CT values ranging from the upper limit of the ECLIA-CT reference range to $100 \mathrm{pg} / \mathrm{mL}$. All patients whose ECLIA-CTs were greater than $100 \mathrm{pg} / \mathrm{mL}$ had MTC or PNET. All MTC patients whose ECLIA-CTs were within the reference range had already undergone total thyroidectomy before collecting serum samples for the present study. When excluding ten patients with MTC or PNET from the 334 patients, 96\% of the remaining 324 patients had ECLIA-CTs within the reference range. Kahaly et al. also analyzed ECLIA-CTs in patients with untreated and/or persistent MTC or Ccell hyperplasia and in those with thyroid nodules, primary hyperparathyroidism, toxic adenoma, GD, HT, and renal failure with secondary hyperparathyroidism. They reported that reference cutoff values were $6 \mathrm{ng} / \mathrm{L}$ for females and $13.3 \mathrm{ng} / \mathrm{L}$ for males [14]. In the present study, other than MTC or PNET, there were only four cases whose ECLIA-CTs were above the cutoff values suggested by Kahaly et al. Although employing a nonECLIA measurement technique (reference range; $\leq 10 \mathrm{pg} / \mathrm{mL}$ ), Costante et al. studied basal serum CT levels in a cohort of 5,817 patients with thyroid nodules using chemiluminescence assay [39]. They reported that MTCs were diagnosed in all nine patients who had basal CT $>100 \mathrm{pg} / \mathrm{mL}$, in $25 \%$ of eight patients with CT $\geq 50$ and $<100 \mathrm{pg} / \mathrm{mL}$, and in $8 \%$ of 49 patients with CT $\geq 20$ and $<50 \mathrm{pg} / \mathrm{mL}$. They also reported that the 216 patients whose CT level was $>10$ and $<20 \mathrm{pg} / \mathrm{mL}$ were followed for up to four years, and only one case with C-cell hyperplasia emerged. Daniels mentioned in his review that it was important to be aware that there are many patients with serum CT $>10 \mathrm{pg} / \mathrm{mL}$, without C-cell pathology [40]. These results, taken together with those of the current study, suggest that patients whose ECLIA-CTs are between the reference range upper limit and $100 \mathrm{pg} / \mathrm{mL}$ require observation or further examination, such as calcium stimulation test. Kihara et al. proposed the reference upper limits of stimulated ECLIA-CT before thyroidectomy to be $67.6 \mathrm{pg} / \mathrm{mL}$ for female [41], and $83.7 \mathrm{pg} / \mathrm{mL}$ for male patients with non-MTC [42].

In conclusion, the results of the present study showed that ECLIA-CT had a good correlation with traditional RIA-CT, though more specific CT levels could be measured using ECLIA, especially among the non-MTC cases after total thyroidectomy. It was also revealed that ECLIA-CTs were undetectable in most samples from patients who were not clinically diagnosed as having MTC. However, we believe that careful attention should be paid in differential diagnosis especially in cases with chronic renal failure or positive-TgAb, when ECLIA-CT is increased up to $100 \mathrm{pg} / \mathrm{mL}$.

\section{Acknowledgments}

We are grateful to Prof. Tetsuya Ohira (Department of Epidemiology, Fukushima Medical University) for his helpful advice on our statistical analyses.

\section{Disclosure}

This study was funded by Roche Diagnostics K.K. The sponsor had no control over the interpretation, writing, or publication of this work. The study was approved by the ethical committee of Fukushima Medical University (No. 2513).

\section{References}

1. Lumachi F, Brunello A, Roma A, Basso U (2008) Medical treatment of malignancy-associated hypercalcemia. Curr Med Chem 15: 415-421.

2. Copp DH, Cheney B (1962) Calcitonin-a hormone from the parathyroid which lowers the calcium-level of the blood. Nature 193: 381-382.

3. Copp DH, Cameron EC, Cheney BA, Davidson AG, Henze KG (1962) Evidence for calcitonin - a new hormone from the parathyroid that lowers blood calcium. Endocrinology 70: 638-649.
4. Prieto S, Perez-Gutierrez A, Tamarit J (1979) Standardization and clinical application of a radioimmunoassay for human calcitonin. Rev Esp Fisiol 35: 21-27.

5. Body JJ, Heath H 3rd (1984) "Nonspecific" increases in plasma immunoreactive calcitonin in healthy individuals: discrimination from medullary thyroid carcinoma by a new extraction technique. Clin Chem 30: 511-514.

6. Tashijan AH Jr, Howland BG, Melvin KE, Hill CS Jr (1970) Immunoassay of human calcitonin. N Engl J Med 283: 890-895. 
7. Becker KL, Nylen ES, White JC, Muller B, Snider RH Jr (2004) Clinical review 167: procalcitonin and the calcitonin gene family of peptides in inflammation, infection, and sepsis: a journey from calcitonin back to its precursors. J Clin Endocrinol Metab 89: 1512-1525.

8. Wells SA Jr, Asa SL, Dralle H, Elisei R, Evans DB, et al. (2015) Revised American Thyroid Association guidelines for the management of medullary thyroid carcinoma. Thyroid 25: 567-610.

9. Kitagawa W, Goto M, Miyazaki N, Tanaka K, Yoshimura $\mathrm{H}$, et al. (2014) Basic and clinical evaluation of EClusys calcitonin assay. Jpn J Med Pharm Sci 72: 97-108 (In Japanese).

10. Matsuo S, Imai E, Horio M, Yasuda Y, Tomita K, et al. (2009) Revised equations for estimated GFR from serum creatinine in Japan. Am J Kidney Dis 53: 982-992.

11. Kidney Disease Improving Global Outcomes (2013) KDIGO 2012 clinical practice guideline for the evaluation and management of chronic kidney disease. Kidney Int 3: $1-150$.

12. Kratzsch J, Petzold A, Raue F, Reinhardt W, BrockerPreuss M, et al. (2011) Basal and stimulated calcitonin and procalcitonin by various assays in patients with and without medullary thyroid cancer. Clin Chem 57: 467474.

13. Kaczka K, Mikosinski S, Fendler W, Celnik A, Pomorski L (2012) Calcitonin and procalcitonin in patients with medullary thyroid cancer or bacterial infection. Adv Clin Exp Med 21: 169-178.

14. Kahaly GJ, Algeciras-Schimnich A, Davis TE, Diana T, Feldkamp J, et al. (2017) United States and European multicenter prospective study for the analytical performance and clinical validation of a novel sensitive fully automated immunoassay for calcitonin. Clin Chem 63: 1489-1496.

15. Seth R, Motte P, Kehely A, Wimalawansa SJ, Self CH, et al. (1988) A sensitive and specific two-site enzymeimmunoassay for human calcitonin using monoclonal antibodies. J Endocrinol 119: 351-357.

16. Motte P, Vauzelle P, Gardet P, Ghillani P, Caillou B, et al. (1988) Construction and clinical validation of a sensitive and specific assay for serum mature calcitonin using monoclonal anti-peptide antibodies. Clin Chim Acta 174: 3554.

17. d'Herbomez M, Caron P, Bauters C, Do Cao C, Schlienger JL, et al. (2007) Reference range of serum calcitonin levels in humans: influence of calcitonin assays, sex, age, and cigarette smoking. Eur J Endocrinol 157: 749-755.

18. Machens A, Hoffmann F, Sekulla C, Dralle H (2009) Importance of gender-specific calcitonin thresholds in screening for occult sporadic medullary thyroid cancer. Endocr Relat Cancer 16: 1291-1298.

19. Guyetant S, Rousselet MC, Durigon M, Chappard D, Franc B, et al. (1997) Sex-related C cell hyperplasia in the normal human thyroid: a quantitative autopsy study. J Clin Endocrinol Metab 82: 42-47.
20. Lissak B, Baudin E, Cohen R, Barbot N, Meyrier A, et al. (1998) Pentagastrin testing in patients with renal insufficiency: normal responsivity of mature calcitonin. Thyroid 8: 265-268.

21. Simmons RE, Hjelle JT, Mahoney C, Deftos LJ, Lisker W, et al. (1988) Renal metabolism of calcitonin. Am J Physiol 254: F593-F600.

22. Lee JC, Parthemore JG, Deftos LJ (1977) Immunochemical heterogeneity of calcitonin in renal failure. $J$ Clin Endocrinol Metab 45: 528-533.

23. Silva OL, Becker KL, Shalhoub RJ, Snider RH, Bivins LE, et al. (1977) Calcitonin levels in chronic renal disease. Nephron 19: 12-18.

24. Karanikas G, Moameni A, Poetzi C, Zettinig G, Kaserer $\mathrm{K}$, et al. (2004) Frequency and relevance of elevated calcitonin levels in patients with neoplastic and nonneoplastic thyroid disease and in healthy subjects. $J$ Clin Endocrinol Metab 89: 515-519.

25. Schuetz M, Beheshti M, Oezer S, Novotny C, Paul M, et al. (2006) Calcitonin measurements for early detection of medullary thyroid carcinoma or its premalignant conditions in Hashimoto's thyroiditis. Anticancer Res 26: 723727.

26. Grani G, Nesca A, Del Sordo M, Calvanese A, Carbotta $\mathrm{G}$, et al. (2012) Interpretation of serum calcitonin in patients with chronic autoimmune thyroiditis. Endocr Relat Cancer 19: 345-349.

27. Durante C, Tognini S, Montesano T, Orlandi F, Torlontano M, et al. (2014) Clinical aggressiveness and long-term outcome in patients with papillary thyroid cancer and circulating anti-thyroglobulin autoantibodies. Thyroid 24: 1139-1145.

28. Vasileiadis I, Boutzios G, Charitoudis G, Koukoulioti E, Karatzas T (2014) Thyroglobulin antibodies could be a potential predictive marker for papillary thyroid carcinoma. Ann Surg Oncol 21: 2725-2732.

29. Toledo SP, Lourenco DM Jr., Santos MA, Tavares MR, Toledo RA, et al. (2009) Hypercalcitoninemia is not pathognomonic of medullary thyroid carcinoma. Clinics (Sao Paulo) 64: 699-706.

30. Rosario PW, Calsolari MR (2013) Influence of chronic autoimmune thyroiditis and papillary thyroid cancer on serum calcitonin levels. Thyroid 23: 671-674.

31. Papapetrou PD, Polymeris A, Karga H, Vaiopoulos G (2006) Heterophilic antibodies causing falsely high serum calcitonin values. $J$ Endocrinol Invest 29: 919-923.

32. Body JJ, Demeester-Mirkine N, Borkowski A, Suciu S, Corvilain J (1986) Calcitonin deficiency in primary hypothyroidism. J Clin Endocrinol Metab 62: 700-703.

33. Borges MF, Abelin NM, Menezes FO, Dahia PL, Toledo SP (1998) Calcitonin deficiency in early stages of chronic autoimmune thyroiditis. Clin Endocrinol (Oxf) 49: 69-75.

34. Lima MA, Santos BM, Borges MF (1998) Quantitative analysis of C cells in Hashimoto's thyroiditis. Thyroid 8: 505-509.

35. Poppe K, Verbruggen LA, Velkeniers B, Finne E, Body JJ, et al. (1999) Calcitonin reserve in different stages of 
atrophic autoimmune thyroiditis. Thyroid 9: 1211-1214.

36. Coners K, Woods SE, Webb M (2011) Dual paraneoplastic syndromes in a patient with small cell lung cancer: a case report. J Med Case Rep 5: 318.

37. Pratz KW, Ma C, Aubry MC, Vrtiska TJ, Erlichman C (2005) Large cell carcinoma with calcitonin and vasoactive intestinal polypeptide-associated Verner-Morrison syndrome. Mayo Clin Proc 80: 116-120.

38. Sim SJ, Glassman AB, Ro JY, Lee JJ, Logothetis CJ, et al. (1996) Serum calcitonin in small cell carcinoma of the prostate. Ann Clin Lab Sci 26: 487-495.

39. Costante G, Meringolo D, Durante C, Bianchi D, Nocera M, et al. (2007) Predictive value of serum calcitonin levels for preoperative diagnosis of medullary thyroid carcinoma in a cohort of 5817 consecutive patients with thyroid nodules. J Clin Endocrinol Metab 92: 450-455.
40. Daniels GH (2011) Screening for medullary thyroid carcinoma with serum calcitonin measurements in patients with thyroid nodules in the United States and Canada. Thyroid 21: 1199-1207.

41. Kihara M, Miyauchi A, Kudo T, Hirokawa M, Miya A (2016) Reference values of serum calcitonin with calcium stimulation tests by electrochemiluminescence immunoassay before/after total thyroidectomy in Japanese patients with thyroid diseases other than medullary thyroid carcinoma. Endocr J 63: 627-632.

42. Kihara M, Miyauchi A, Kudo T, Hirokawa M, Miya A (2018) Serum calcitonin reference values for calcium stimulation tests by electrochemiluminescence immunoassay in Japanese men with non-medullary thyroid carcinoma. Surg Today 48: 223-228. 